\title{
Comparison of Single-Payer and Non Single-Payer Health Care Systems: A Study of Health Administration Efficiency
}

\author{
Jia Yu', Yi Zhang² \\ ${ }^{1}$ Christopher Newport University, Newport News, USA \\ ${ }^{2}$ Discover Financial Services, Phoenix, USA \\ Email: jia.yu@cnu.edu, yizhang@discover.com
}

How to cite this paper: $\mathrm{Yu}, \mathrm{J}$. and Zhang Y. (2017) Comparison of Single-Payer and Non Single-Payer Health Care Systems: A Study of Health Administration Efficiency. Modern Economy, 8, 816-833.

https://doi.org/10.4236/me.2017.86057

Received: May 22, 2017

Accepted: June 19, 2017

Published: June 22, 2017

Copyright $\odot 2017$ by authors and Scientific Research Publishing Inc. This work is licensed under the Creative Commons Attribution International License (CC BY 4.0).

http://creativecommons.org/licenses/by/4.0/

(c) (i) Open Access

\begin{abstract}
The United States spends nearly twice as much per capita on health care as several OECD countries. Based on previous research, universal health care decreases the total health care expenditure due to the single-payer system; it is still unknown whether a mixed health care system has superiority. In this study, we compare and evaluate both quality of care and administrative costs among six developed countries, upon three groups: single-payer universal health care system (Australia and Canada), two-tier health care system (France and Japan), and insurance mandate health care system (Switzerland and the US). The results show that both single-payer system and two-tier system are superior to insurance mandate system on health insurance administration costs. Also, regarding insurance mandate system, the healthcare system in Switzerland is more efficient than that in the US. So, we conclude that it is possible for the US to choose a diverse healthcare system, instead of focusing on one system, to trim the healthcare administration cost and improve the quality of care for the entire country.
\end{abstract}

\section{Keywords}

Health Administration Cost, OECD, Data Envelope Analysis, Single-Payer System, Two-Tier Health System, Insurance Mandate System

\section{Introduction}

In 1991, Woolhandler and Himmelstein [1] reported that people in the United States spent about $\$ 450$ per capita on healthcare administration in 1997, whereas Canadians spent one third as much. In 2009, healthcare spending in the US reached $\$ 8015$ per capita, versus only $\$ 4269$ in Canada. Data from the OECD 
show that the US spent $17.1 \%$ of its GDP on health care in 2009 . This was almost $50 \%$ more than the next-highest spender (Germany $11.75 \%$ of GDP) and almost double what was spent in the UK (9.73\%) [2]. Meanwhile, OECD data also showed that administration costs in the US health care are the highest in the developed countries, accounting for nearly $8 \%$ of healthcare spending, over $\$ 650$ per capita in 2011 (Figure 5 \& Figure 6). Globally, health care systems spend about $3 \%$ on average on administration cost. In 2010, the Patient Protection and Affordable Care Act, called PPACA or ACA but also known as Obamacare, was enacted, providing for the phased introduction over multiple years of a comprehensive system of mandated health insurance reforms designed to eliminate "some of the worst practices of the insurance companies". Healthcare spending growth has slowed in the US since 2009. The real growth rate per capita in the US declined from $2.47 \%$ between 2003 and 2009 to $1.5 \%$ between 2009 and 2013 [3]. Obamacare also helped to reduce non-medical spending in the sector, and resulting in $\$ 3.7$ billion in savings between 2011 and 2013 [4]. However, despite its heavy investment in health care, the US still have poor results on several key health outcome measures, such as life expectancy, the prevalence of chronic conditions, and avoidable mortality [2] [3].

Based on the data analysis from OECD, US devotes a large percentage of its GDP on healthcare and a large percentage of its healthcare expenditure to administration than any other country, but with a relatively low and poor health outcomes. Continuing on the research testing healthcare expenditure efficiency in 2016 [2], we would like to study about the efficiency of healthcare administration costs among different healthcare systems and provide suggestions on the direction of future healthcare reforms for the US. When studying the way that health care is organized in different countries, one of the major questions is whether private or public systems are preferable.

Generally, there are three types of healthcare payment systems over the world, single-payer system, two-tire system, and insurance mandate system. Single payer system healthcare is a system in which the state, rather than private insurers, pays for all healthcare costs. The term "single payer" describes the funding mechanism, referring to healthcare financed by a single public body from a single fund. Many nations worldwide have single-payer health insurance programs. In our research, we choose Canada and Australia as the representative of single-payer healthcare system. Healthcare in Canada is delivered through a publicly funded health care system, informally called Medicare, which is mostly free at the point of use and has most services provided by private entities. Under the Canadian Health Act, all citizens are guaranteed government-sponsored health insurance. Provinces and territories in Canada have primary responsibility for organizing and delivering health services and supervising providers. The provinces and territories administer their own universal health insurance programs, covering all provincial and territorial residents according to their own residency requirements [5]. The main funding sources are general provincial and territorial spending, which was forecast to constitute $93 \%$ of public health spending in 
2015 [6]. However, the healthcare in Canada is not a strict single-payer system. Excluding the public reimbursement, private insurance starts to play a role on covering citizens' healthcare expenses. Similar as Australia, this is not a strict single-payer system either. The government is still the major fund source to support the states, and health professions, subsiding primary care providers through different programs. The federal government funds Medicare, a universal public health insurance program providing free or subsidized access to care for Australian citizens and residents [7]. We treat these two countries as the representative of single-payer system due to two reasons: 1) government is the major funding source; 2) public financed healthcare services are free to residents.

Two-tier healthcare system is a situation in which a basic government-provided healthcare system provides basic care, and a secondary tier of care exists for those who can pay for additional better quality or faster access. Most of countries have both publicly and privately funded healthcare (even including Canada and Australia), but the degree to which creating a quality differential depends on the way the two systems are managed, funded and regulated. We choose France and Japan to explain the two-tier healthcare system. Healthcare in France is a system of private and public physicians, who largely draws their income from the government. Patients pay a small copayment for certain aspects of care, and many people choose to cover the costs by taking out supplemental health insurance for which a small premium is payable each year. France has a two-tier funding arrangement, with compulsory funding of core medical services from taxation, with optional private insurance for the cost of copayments and premiums. Healthcare in Japan is regulated by government through the universal public health insurance system (PHIS). The national and local governments are required by law to ensure a system that efficiently provides good-quality and well-suited medical care to the nation. The PHIS, comprising more than 3,400 insurers, provides universal primary coverage [8]. Citizens are mandated to enroll in one of the PHIS plans based on employment status and/or place of residence, paying with certain amount of premium. Even the private health insurance plays a complementary role to support Japanese medical needs; the entire payment system includes government funding and private payment.

Insurance mandate healthcare system is either an employer or individual mandate to obtain private health insurance which instead of (or in additional to) a national health insurance plan. In this part, we select Switzerland and the United States as the representative. Especially, the major goal for this research is to compare the inefficiency of the US healthcare system with others. Healthcare in Switzerland is universal and is regulated by the Swiss Federal Law on Health Insurance. There are no free state-provided health services, but private health insurance is compulsory for all persons residing in Switzerland. Health insurance covers the costs of medical treatment and hospitalization of the insured. The insured person pays part of the cost of treatment. The healthcare system in the US, after the most recent healthcare reform, established "shared responsibility" between the government, employers, and individuals for ensuring that all 
Americans have access to affordable and good-quality health insurance. However, health coverage remains fragmented, with numerous private and public sources as well as wide gaps in insured rates across the US population. United States has a quite similar healthcare system as Switzerland. If we are able to prove Switzerland is capable to utilize their administration costs more efficiently than the United States.

The major research goal for our study is testing whether the healthcare administration costs are efficient or not among three healthcare systems, in six countries. We would like to supply an empirical proof to support more options for the US healthcare system reform in the future, using a non-parametric analysis methodology. We summarize several previous studies about healthcare administration costs among different countries, using varieties of methods in Section 2. We explain the data and empirical model used in this research in Section 3. In Section 4, we illustrate the results. In Section 5, we conclude and discuss our results and provide suggestion for future healthcare reforms in the United States.

\section{Literature Review}

So far, there is no conclusion about which healthcare system is the most efficient. But plenty of studies have compared those different healthcare systems by looking at diverse healthcare indicators and performances. Among those studies, Ellis, Chen, and Luscombe [9] provided a comprehensive evaluation on different types of healthcare systems, represented by five developed countries. Their study discussed about the comparisons from healthcare agents and choices, coverage and national expenses, revenue, cost control, specialized insurance programs, as well as the comparisons among different countries representing those different healthcare systems. Unfortunately, their paper didn't reach a conclusion which healthcare system was prior to the others but mentioned about the hardship of identifying the most effective healthcare system in the world by utilizing what were feasible in the current research sources.

Similarly, E. Mossialos, M. Wenzl, R. Osborn and Sarnak, D. [10] [11] provided a more detailed overview of different healthcare systems among eighteen countries including both developed and developing countries, with more healthcare indicators compared. Among those indicators, the total healthcare spending showed that US had the highest healthcare-spending share of GDP comparing with the other countries.

US high healthcare cost and inefficient system is also indicated by DPE Fact Sheet [11]. The fact sheet compared US health care system to other OECD countries in terms of healthcare costs and insurance coverage, finding that US had healthcare expenditure as double as the average of all OECD countries. It also pointed out that one of the main contributors of US high healthcare spending came from administration costs, which is the main objective our paper discusses.

Ridic, Gleason and Ridic [12] examined the difference of healthcare systems 
among US, Canada and Germany. They also discussed about the pros and cons of national health insurance program, social insurance program and private insurance program, represented by Canada, Germany and US respectively. They claimed that US healthcare system was beneficial for extending life expectancy for people over 80 years old as well as fostering pharmaceutical innovation. However, US healthcare system had its flaws such as creating lack of health insurance for certain group of people as well as the hardship of controlling costs. Also, the paper noticed that people in the US were the least satisfied with their healthcare system, while Canadian was the most satisfied.

Medeiros and Schwierz [10] conducted similar research on the relative efficiency of healthcare systems across all EU countries by applying an input-output method. They calculated the efficiency score by looking at the life expectancy and mortality rate as the output by inputting healthcare expenditure, physical inputs and environmental variables. Their paper found inconsistency of the healthcare efficiency across different EU countries, among which some European countries have higher efficiency scores than others.

Moreover, several studies have proved that the healthcare administration costs are a main reason for healthcare inefficiency. For instance, Woolhandler, Campbell and Himmelstein [1] calculated the healthcare administrative costs between US and Canada by looking at the healthcare expenses from insurers, employers' health benefits program, hospitals, practitioners' offices, nursing homes, and home care agencies. They found in the US, the total administrative costs were $\$ 750+$ per capita more than Canada, which indicated Canadian's single payer system was more efficient.

Pozen and Cutler [13] reached the similar conclusion by comparing the difference of incomes, administration, and medical interventions between US and Canada. They also provided the evidence that administration costs caused the largest difference of healthcare spending between these two countries. They applied a counterfactual approach by multiplying US spending to the percentage difference of spending between US and Canada to calculate the potential savings for US if it spends like Canada.

This paper tries to build the bridge between the comparisons among different healthcare systems and administration costs as the contributor using an innovative technical efficiency analysis methodology. We compare the technical efficiency score of healthcare administration cost in 6 countries within three healthcare systems (single-payer, two-tier, and insurance mandate). Our research provides a solid evidence to proof that the U.S. is possible to learn and apply the experiences from not only single-payer system, but also two-tier system and insurance mandated system.

\section{Data and Econometric Model}

We use data from OECD statistics in 2011 with information on 6 countries, categorized into 3 health care systems. The reason why we focus on 2011 is because we have the most reliable and sufficient data about these 6 countries in 2011 . 
Single-payer system includes Canada and Japan; two-tier system includes Australia and France; and insurance mandate system includes Switzerland and the US. Table 1 summarizes the essential data on health expenditure for these 6 countries in 12 years (2000-2012).

In this paper, the efficiency of health expenditure is evaluated by life expectancy at birth and number of live births. The efficiency of health administration cost here means its success in increasing the life expectancy at birth or number of live births as much as possible for a given amount of health administration cost (input oriented), or its success in decreasing health administration cost as much as possible for a given life expectancy or given number of live births (output oriented). Provided that all inputs and outputs are correctly measured, this interpretation is widely accepted.

The 10-year statistics relationship between inputs (health administration costs) and outputs (life expectancy and number of live birth) is illustrated through Figures 1-4. Figure $1 \&$ Figure 2 display the influence from health administration costs (two measurements) on life expectancy in these 6 countries over 12 years. The life expectancy of 6 countries is very similar and close. Figure $3 \&$ Figure 4 show the effects on number of live births from health administration costs in 6 countries over 12 years. The number of live births is very close for 6 countries and stable over 12 years. Meanwhile, the healthcare administration expenditure increases over years, especially the United States. Also, the United States is always ranked top 1 on health administration expenditure.

To illustrate the economic efficiency of health administration costs on evaluating the two health indicators (life expectancy and number of live births), we compare this specific influence among 6 countries in year of 2011. Figure 5 \& Figure 6 represent the one-year comparison among 6 countries. We could have similar conclusion from one-year comparison as the multiple-year comparison. United States spent the most on healthcare expenditure and healthcare administration. Among 6 countries, the United States has the lowest life expectancy, and Japan has the lowest number of live births. After summarizing the data and explaining the relationships and influences, even we can easily conclude that the

Table 1. Descriptive statistics (Total).

\begin{tabular}{cccccc}
\hline Variable & $\mathrm{N}$ & mean & $\mathrm{sd}$ & $\min$ & $\max$ \\
\hline Life_Expec $\sim \mathrm{h}$ & 82 & 80.662 & 1.706 & 76.700 & 83.400 \\
Live_Birth $\sim \mathrm{t}$ & 80 & 1.157 & 0.182 & 0.819 & 1.433 \\
Health_Adm $\sim \mathrm{t}$ & 83 & 4.647 & 1.991 & 1.534 & 8.130 \\
Health_Adm $\sim \mathrm{a}$ & 83 & 206.746 & 160.041 & 42.454 & 666.143 \\
Public_per t & 83 & 2.561 & 0.923 & 1.239 & 5.263 \\
Public_Cap a & 83 & 106.457 & 62.501 & 36.130 & 299.998 \\
Private_pe t & 83 & 2.086 & 1.376 & 0.265 & 5.309 \\
Private_Ca a & 83 & 100.289 & 103.175 & 5.708 & 366.145 \\
\hline
\end{tabular}

Data Source: OECD statistics. 

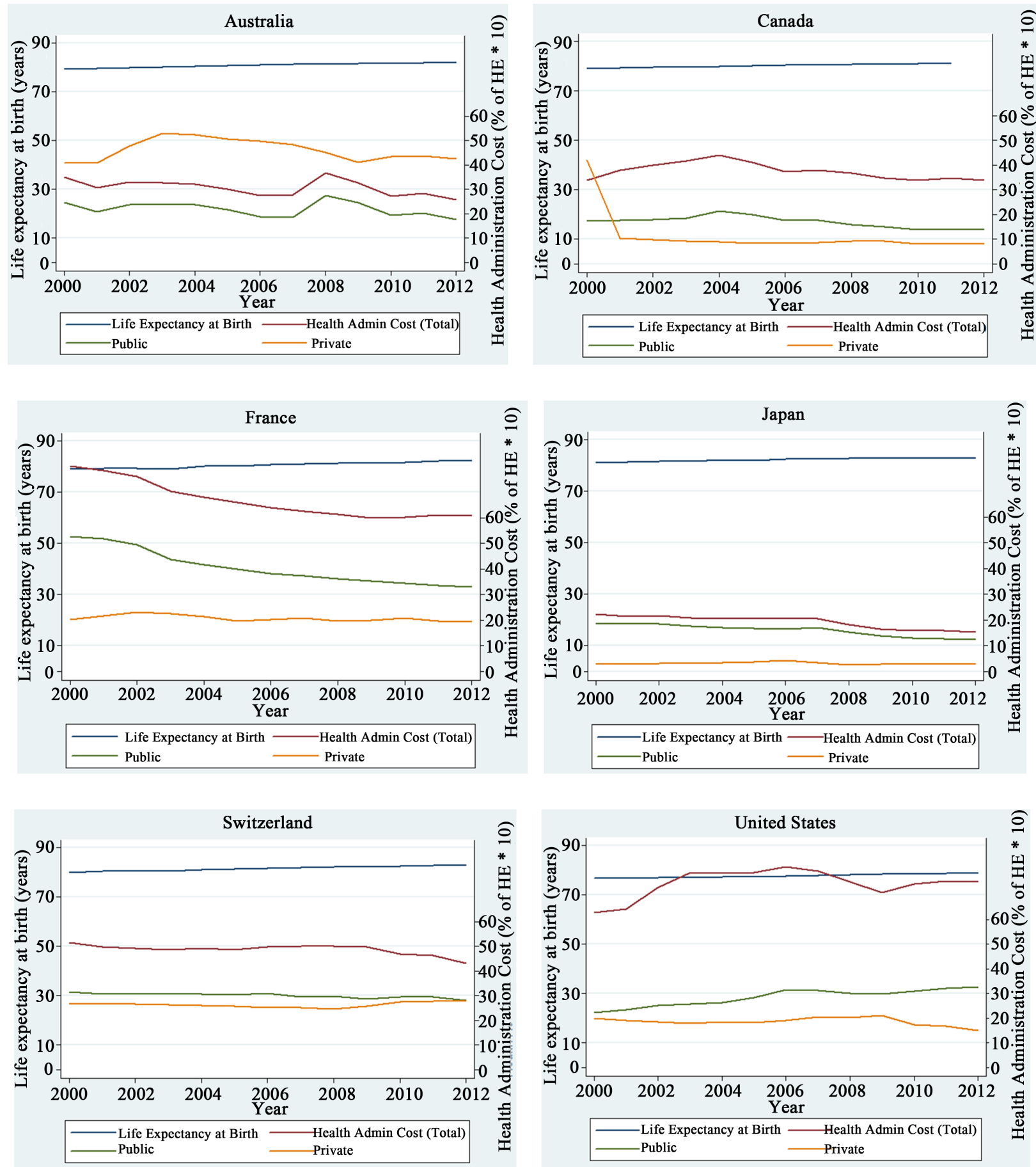

Figure 1. Comparison over years (Life expectancy and health admin cost (\% of Health Expenditure)). Source: OECD statistics.

US spend way more than the other countries on healthcare. But we cannot prove that the US applies the healthcare spending inefficiently, just through the statistical analysis. We will test the economic efficiency of healthcare administration spending using a non-parametric methodology then.

Economics efficiency is a combination of both technical efficiency (output with least input) and allocative efficiency (resources allocation for greatest-valued uses). This paper looks for the highest life expectancy and live birth amount 

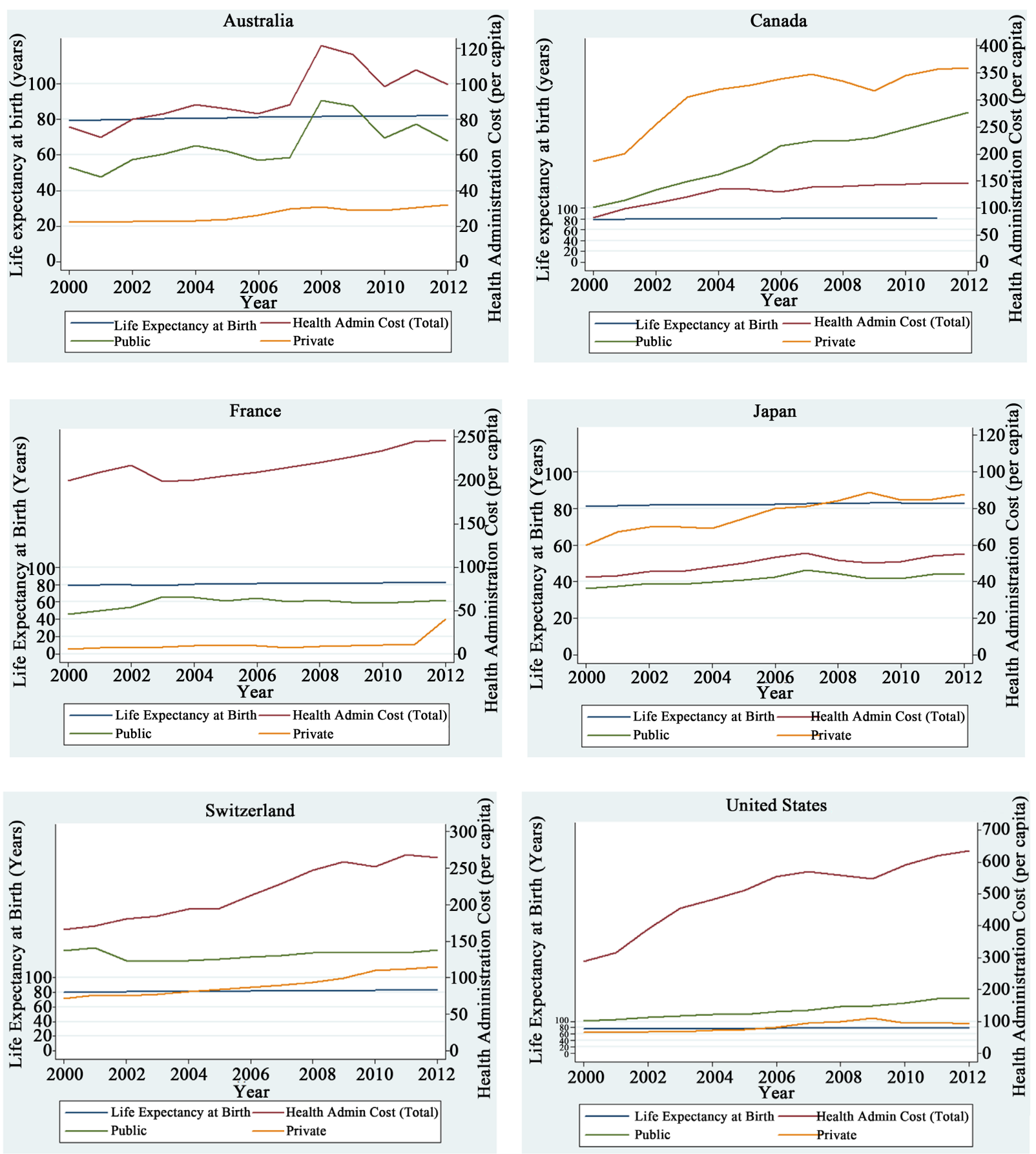

Figure 2. Comparison over years (Life expectancy and health admin cost (per capita)). Source: OECD statistics.

with the least health administration costs for different healthcare systems. The definition and concept limits the focus of this study to the measurement of technical efficiency.

We apply a non-parametric method that allows the estimation of efficiency frontier and efficiency losses-Data Envelopment Analysis (DEA). This method is generally applied to decision-making units, by the firms, or non-profit or public organizations that convert inputs into outputs. This methodology, DEA, originating from Farrell's (1957) seminal work and popularized by Charnes, Cooper 

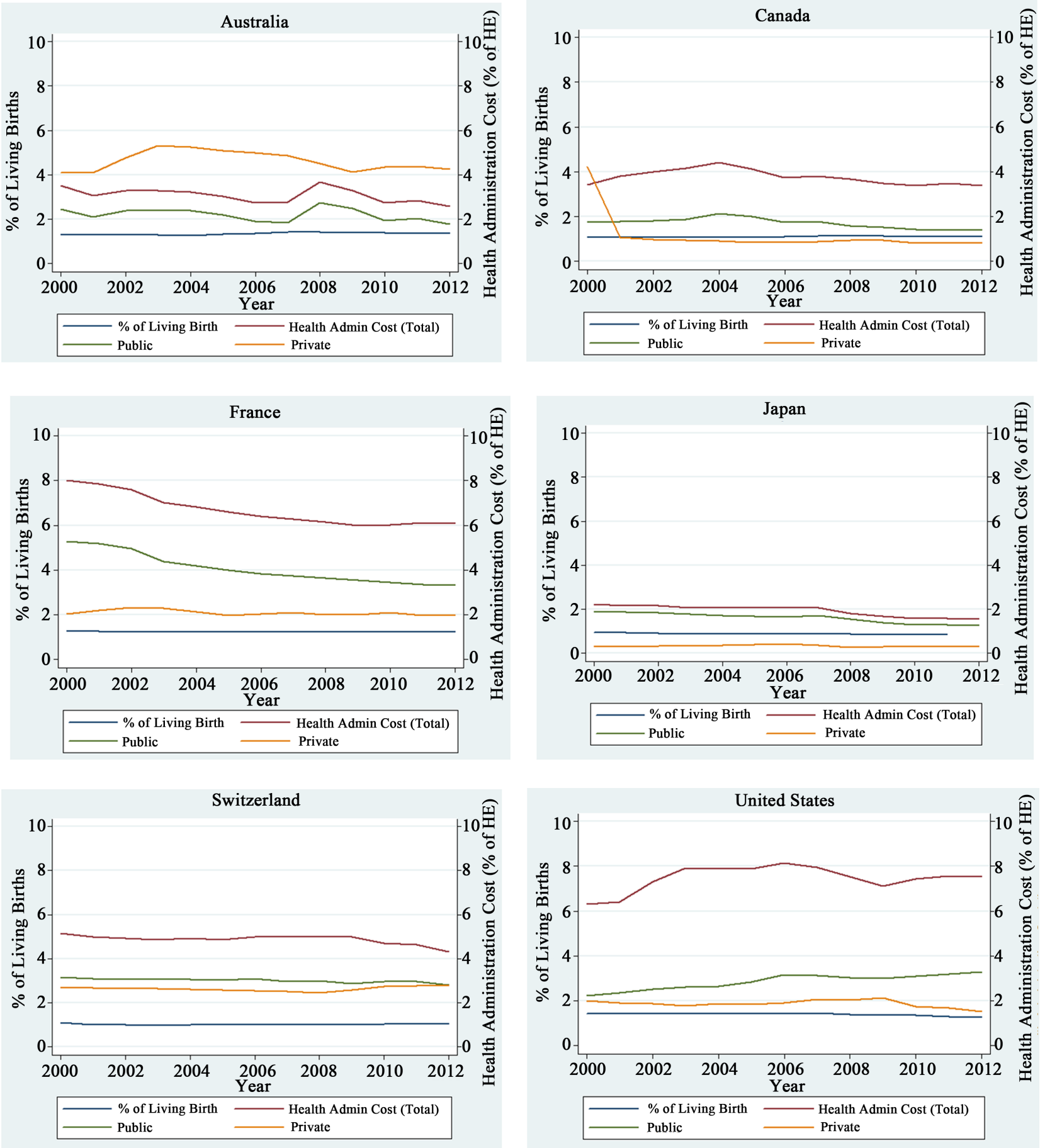

Figure 3. Comparison over years (Live births and health admin costs (\% of Health expenditure)). Source: OECD statistics.

and Rhodes [14], assumes the existence of a convex production frontier and accommodates multiple inputs and outputs without the requirement for a common denominator of measurement. DEA is particularly well-suited for analyzing the technical efficiency of health spending, as we used one input to produce multiple outputs, based on the observed relationship between health administration cost and quality of care. The production frontier in the DEA approach is constructed using linear programming. An empirical piece-wise linear frontier, 

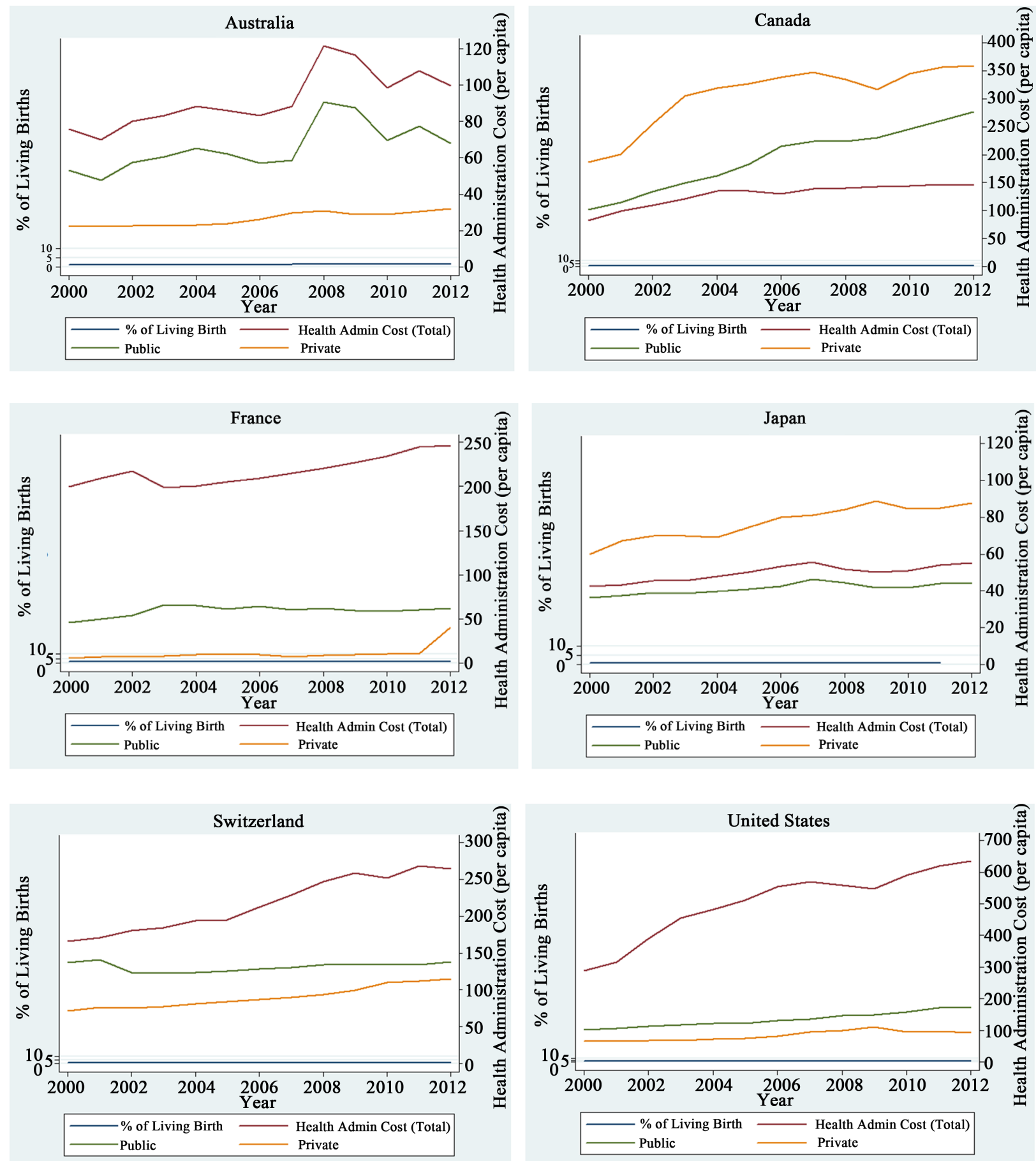

Figure 4. Comparison over years (Live births and health admin cost (per capita)). Source: OECD statistics.

i.e. "best practice frontier", isolates potential efficient units (points on the frontier) from inefficient units (all points enveloped by the frontier) [15].

The measurement of technical efficiency using DEA depends on the assumed types of returns to scale. Returns to scale refers to the changes in output when all inputs change by the certain proportion. Constant returns to scale (CRS) means proportion changes in input will lead to same proportionate changes in output. And variable returns to scale (VRS) means the same proportion changes in input 

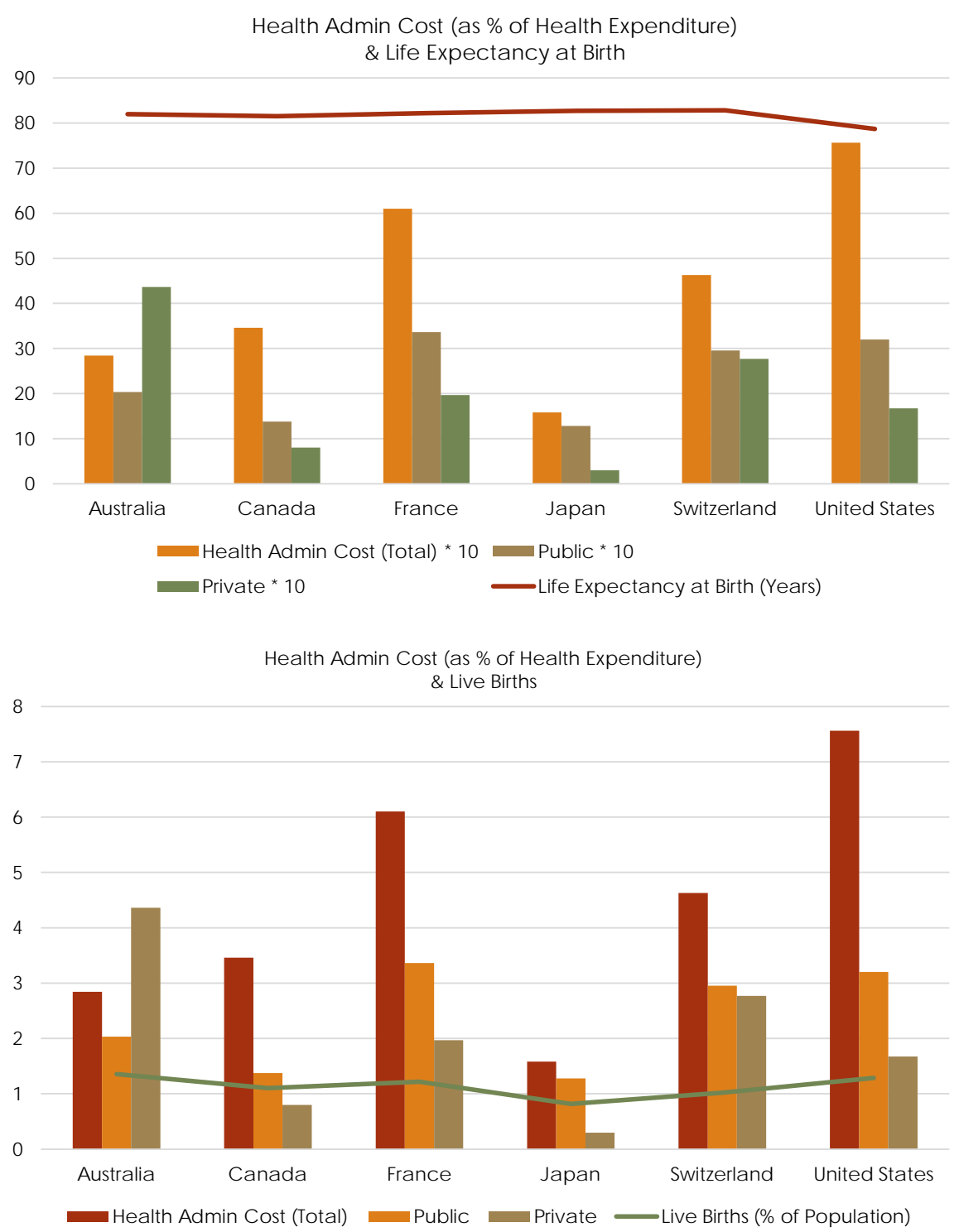

Figure 5. Comparison over countries in 2011 (Measure: \% of health expenditure). Source: OECD statistics.

will lead to disproportionate changes in outputs, including increasing returns to scale (IRS) and decreasing returns to scale (DRS). Charnes, Cooper and Rhodes [14] developed DEA as a way to measure technical efficiency under constant returns to scale. However, the CRS model is not able to distinguish between scale efficiency and pure technical efficiency. In 1984, Banker [16], Charnes and Cooper revised the model to measure technical efficiency under VRS, and capture the scale efficiency of each unit. Scale efficiency is then obtained by dividing each country's CRS technical efficiency score by its VRS technical efficiency score.

The overall shape of the frontier depends on the production possibility set, i.e. the assumption made for attainable points. The efficient units will be those that have an efficiency score of 1 (or 100\%) and the inefficient ones will be those with efficiency scores less than 1 (or 100\%). 


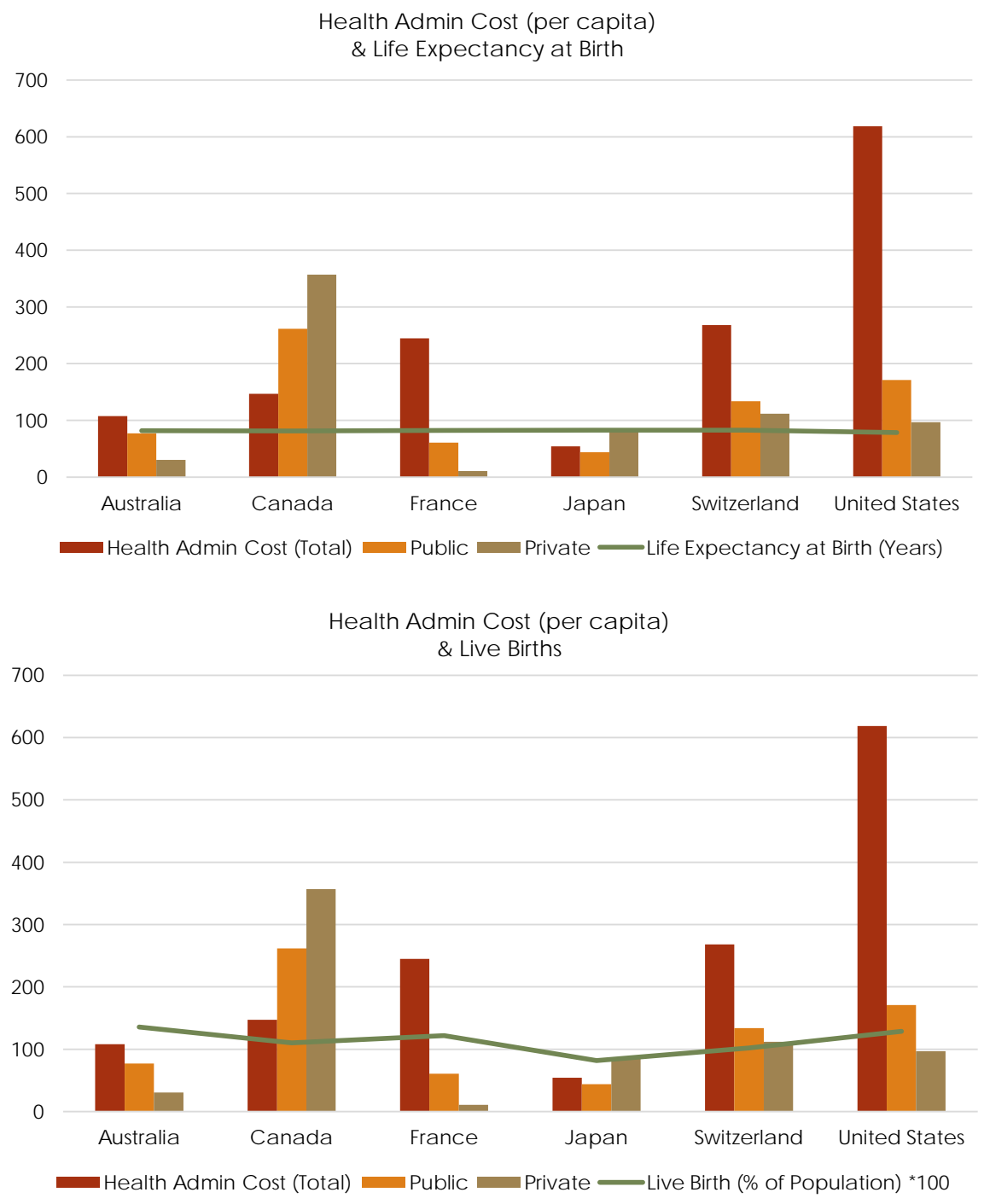

Figure 6. Comparison over countries in 2011 (Measure: health admin cost per capita). Source: OECD statistics.

DEA also has the calculation of technical efficiency measures that can be either input or output oriented. The purpose of an input-oriented study is to evaluate by how much input quantity can be proportionally reduced without changing the output quantities. Alternatively, by computing output-oriented measures, one could try to assess how much output quantities can be proportionally increased without changing the input quantities used. The two measures provide the same results under constant returns to scale but give different values under variable returns to scale. Nevertheless, both output and input-oriented models will identify the same set of efficient/inefficient decision-making units. Based on seminal definitions of efficiency by Farrell (1957), technical efficiency consists of producing the maximum amount of output from a given amount of input, or producing a given amount of output with minimum input quantities, such that when a firm is technically efficient, it operates on its production frontier. 
For comparing life expectancy and live births amount, we decide to use both input-oriented and output-oriented methods. Under the assumption of VRS, the efficiency of country $j$ can be obtained by solving the DEA model [14]:

$$
\operatorname{Max}\left(\sum_{i=1}^{n} u_{i} y_{i j}+u_{0}\right)
$$

subject to

$$
\begin{gathered}
\sum_{k=1}^{N} v_{k} x_{k j}=1 \\
\left(\sum_{i=1}^{n} u_{i} y_{i j}+u_{0}\right)-\sum_{k=1}^{N} v_{k} x_{k j} \leq 0, \forall j=1, \cdots, 6 \\
u_{i}, v_{k} \geq 0
\end{gathered}
$$

where $y_{i j}$ is the amount of output $i$ produced by country $j ; x_{k j}$ is the amount of input $k$ used by country $j u_{i}$ is the weight given to output $i(i=1, \cdots, n)$; $v_{k}$ is the weight given to input $k(k=1, \cdots, N)$.

The first constraint indicates that the weighted sum of inputs for a particular country equals to one. The second constraint shows that all countries are on the frontier or below the frontier. The weights $u_{i}$ and $v_{k}$ are unknown and obtained in the solution to the linear programming problem. The term $u_{0}$ determines the returns to scale: $u_{0}>0$ means increasing returns to scale (IRS), $u_{0}<0$ means decreasing returns to scale (DRS), and $u_{0}=0$ means constant returns to scale (CRS).

In this DEA method, the output variable is life expectancy at birth and live birth amount, and the input variable is health administration cost, which have been measured by two measurements: percentage of total health expenditure and health administration costs per capita. To illustrate the different effects of government expenditure and private sector spending, I also divide the output into two variables, total health administration costs and weighted health administration costs. The details about variables have been illustrated in Table 1 .

\section{Empirical Results}

The DEA model in this research is one-input and multiple-output model, with health administration cost as the input and the quality of care as output. The outcome measure includes life expectancy at birth and live birth amounts. We use two indicators as healthcare administration cost measures: one is health administration cost as a percentage of total healthcare expenditure (indicator_1), and the other is total health administration cost per capita (indicator_2). Health administration cost is expressed in terms of US\$ Purchasing Power Parities (PPP) in order to take into account differences in prices and purchasing power across countries.

Table 2 [DEA results for 2011 (total health admin costs)] reports the technology efficiency score with health administration cost (both indicator_1 and indicator_2) as the main input, and both life expectancy and live birth as the 
Table 2. DEA results for 2011 (Total health admin costs).

\begin{tabular}{cccccccccccccc}
\hline & \multicolumn{3}{c}{ Health Admin Cost (\% of Health Expenditure) } & \multicolumn{3}{c}{ Health Admin Cost (per capita) } \\
\cline { 2 - 12 } Country & \multicolumn{3}{c}{ Input Oriented } & \multicolumn{3}{c}{ Output Oriented } & \multicolumn{3}{c}{ Input Oriented } & \multicolumn{2}{c}{ Output Oriented } \\
\cline { 2 - 13 } & Rank & VRS_TE & CRS_TE & Rank & VRS_TE & CRS_TE & Rank & VRS_TE & CES_TE & Rank & VRS_TE & CRS_TE \\
\hline Australia & 1 & 1.000 & 0.920 & 2 & 1.000 & 0.920 & 1 & 1.000 & 0.832 & 1 & 1.000 & 0.832 \\
Canada & 4 & 0.648 & 0.614 & 5 & 0.989 & 0.614 & 4 & 0.560 & 0.495 & 5 & 0.989 & 0.495 \\
France & 5 & 0.435 & 0.385 & 4 & 0.998 & 0.385 & 5 & 0.426 & 0.329 & 4 & 0.998 & 0.329 \\
Japan & 1 & 1.000 & 1.000 & 1 & 1.000 & 1.000 & 1 & 1.000 & 1.000 & 1 & 1.000 & 1.000 \\
Switzerland & 3 & 1.000 & 0.425 & 3 & 1.000 & 0.425 & 3 & 1.000 & 0.252 & 1 & 1.000 & 0.252 \\
US & 6 & 0.354 & 0.328 & 6 & 0.959 & 0.328 & 6 & 0.163 & 0.138 & 6 & 0.959 & 0.138 \\
\hline
\end{tabular}

Data Source: OECD statistics.

output. A country is efficient when the score equals one. The model is one-input, multiple-output model, and Table 2 has both input-oriented and outputoriented efficiency scores and rankings. Column $3 \&$ Table 4 show the results when the right-hand variable is health administration cost as a percentage of total health expenditure for both input and output-oriented model. Column $9 \& 10$, $12 \& 13$ show the results when health administration cost is expressed in per capita terms. Table 2 shows that three countries are labeled as efficient-Australia, Japan and Switzerland. For each of them, there is no other country where people achieve a better result with fewer resources. For both input-oriented and output-oriented models, the US ranked as the last one of these six countries for both two indicators. For indicator_1, the efficiency score of the US is 0.354 for input-oriented model, i.e. the US was only able to produce $35.4 \%$ output with the same amount of resources other countries used. For indicator_2, the efficiency score of the US is only 0.163 . As the representative of three different healthcare systems, Australia, Japan and Switzerland were all efficient on healthcare administration cost.

We also divided weighted healthcare administration cost into two groups to test the difference between government and private sector. Table 3 [DEA results for 2011 (government weighted)] shows the technology efficiency scores for weighted health administration cost with heavier weighting on government (two indicators). For indicator_1, there are four countries labeled as efficient-Australia, Canada, Japan, and Switzerland. For indicator_2, there are also four countries labeled as efficient-Australia, France, Japan, and Switzerland. Obviously, for both two indicators, the US is inefficient on government-effort healthcare administration cost. Single-payer system is efficient when the input is measured health administration cost as a percentage of healthcare expenditure. Two-tier system is efficient when we evaluate health administration cost per capita. However, Switzerland, as the representative of Insurance Mandate system, is still efficient for both indicator_1 and indicator_2.

Table 4 [DEA results for 2011 (private sector weighted)] reports the efficiency scores for weighted health administration cost with heavier weighting on private 
Table 3. DEA results for 2011 (Government weighted).

\begin{tabular}{|c|c|c|c|c|c|c|c|c|c|c|c|c|}
\hline \multirow{3}{*}{ Country } & \multicolumn{6}{|c|}{ Health Admin Cost (\% of Health Expenditure) } & \multicolumn{6}{|c|}{ Health Admin Cost (per capita) } \\
\hline & \multicolumn{3}{|c|}{ Input Oriented } & \multicolumn{3}{|c|}{ Output Oriented } & \multicolumn{3}{|c|}{ Input Oriented } & \multicolumn{3}{|c|}{ Output Oriented } \\
\hline & Rank & VRS_TE & CRS_TE & Rank & VRS_TE & CRS_TE & Rank & VRS_TE & CRS_TE & Rank & VRS_TE & CRS_TE \\
\hline Australia & 1 & 1.000 & 0.832 & 3 & 1.000 & 0.832 & 1 & 1.000 & 0.874 & 1 & 1.000 & 0.874 \\
\hline Canada & 3 & 1.000 & 1.000 & 2 & 1.000 & 1.000 & 6 & 0.213 & 0.213 & 5 & 0.987 & 0.213 \\
\hline France & 6 & 0.569 & 0.452 & 5 & 0.998 & 0.452 & 1 & 1.000 & 1.000 & 1 & 1.000 & 1.000 \\
\hline Japan & 1 & 1.000 & 1.000 & 1 & 1.000 & 1.000 & 1 & 1.000 & 1.000 & 1 & 1.000 & 1.000 \\
\hline Switzerland & 4 & 1.000 & 0.460 & 4 & 1.000 & 0.460 & 4 & 1.000 & 0.392 & 4 & 1.000 & 0.392 \\
\hline US & 5 & 0.579 & 0.502 & 6 & 0.959 & 0.502 & 5 & 0.403 & 0.374 & 6 & 0.959 & 0.374 \\
\hline
\end{tabular}

Data Source: OECD statistics.

Table 4. DEA results for 2011 (Private sector weighted).

\begin{tabular}{|c|c|c|c|c|c|c|c|c|c|c|c|c|}
\hline \multirow{3}{*}{ Country } & \multicolumn{6}{|c|}{ Health Admin Cost (\% of Health Expenditure) } & \multicolumn{6}{|c|}{ Health Admin Cost (per capita) } \\
\hline & \multicolumn{3}{|c|}{ Input Oriented } & \multicolumn{3}{|c|}{ Output Oriented } & \multicolumn{3}{|c|}{ Input Oriented } & \multicolumn{3}{|c|}{ Output Oriented } \\
\hline & Rank & VRS_TE & CRS_TE & Rank & VRS_TE & CRS_TE & Rank & VRS_TE & CRS_TE & Rank & VRS_TE & CRS_TE \\
\hline Australia & 5 & 1.000 & 0.114 & 5 & 1.000 & 0.114 & 1 & 1.000 & 0.385 & 2 & 1.000 & 0.385 \\
\hline Canada & 2 & 1.000 & 0.503 & 2 & 1.000 & 0.503 & 6 & 0.029 & 0.029 & 5 & 0.987 & 0.029 \\
\hline France & 3 & 1.000 & 0.226 & 3 & 1.000 & 0.226 & 1 & 1.000 & 1.000 & 1 & 1.000 & 1.000 \\
\hline Japan & 1 & 1.000 & 1.000 & 1 & 1.000 & 1.000 & 1 & 1.000 & 0.125 & 3 & 1.000 & 0.125 \\
\hline Switzerland & 4 & 1.000 & 0.135 & 4 & 1.000 & 0.135 & 1 & 1.000 & 0.095 & 4 & 1.000 & 0.095 \\
\hline US & 6 & 1.000 & 0.281 & 6 & 1.000 & 0.281 & 5 & 0.211 & 0.115 & 6 & 0.959 & 0.115 \\
\hline
\end{tabular}

Data Source: OECD statistics.

sector. Column $3 \& 4,6 \& 7$ still indicate the efficiency scores when input is measured as health administration costs as a percentage of healthcare expenditure. In these columns, all countries are efficient on health administration cost application. Column $9 \& 10,12 \& 13$ report the efficiency score when the input is measured as healthcare administration cost per capita. There are four countries labeled efficient-Australia, France, Japan, and Switzerland.

\section{Conclusion and Discussion}

\subsection{Conclusions}

The results allow four types of comparisons:

1) Across six developed countries, I compute efficiency for each of them;

2) Across three healthcare systems, single-payer system, two-tier system, and insurance mandate system;

3) Across two measurements of inputs, health administration cost as a percentage of total healthcare expenditure, and health administration cost per capita;

4) Across two sectors, private and public, to see whether these measures of efficiency and inefficiency are country specific. 
Healthcare systems could be efficient based on different segments. To evaluate total administration expenditure or administration expenditure per capita, there is at least one country showing efficiency in all three healthcare systems: Australia for single-payer system, Japan for two-tier system, and Switzerland for insurance mandate system. To evaluate the administration spending of public sector, both single-payer system and two-tire system show the healthcare administration efficiency. However, when we evaluate the administration expenditure of private sector, all three healthcare systems shows the efficiency on applying healthcare administration costs.

\subsection{Discussion}

The government has proposed fundamental health reforms for years. There are a wide variety of reform models, and a number of different ways to get to universal coverage. Many argue that the only logical approach to such reform is a single-payer system, as in Canada, where one monopoly government insurer provides coverage for the entire population. Learning from single-payer system (like Canada) has been a long-term debate among health economists. This approach has a number of major efficiency advantages, including lower government expenditure, improve quality of care, maximize the bargaining power of the government, make the administration costs application more efficient than the US. Also the biggest disadvantage of this model is the long waiting time for almost everything-to get appointments with physicians, to get tests, to obtain surgeries, etc. In terms of waiting times and bureaucratic hassles, health care for patients may come to resemble the Canadian healthcare system.

Meanwhile, there are economists also said such an approach is highly unlikely to succeed in the US [17]. Gruber claimed that this approach would display the majority of insured Americans who are largely satisfied with the health insurance they receive from their employers, and require nationalizing an industry, private health insurance, with more than $\$ 500$ billion in revenues per year. In this situation, there are also two other choices, such as two-tier system and insurance mandate system.

From the perspective of this article, two-tiered healthcare system also shows the efficiency of healthcare administration costs, especially Japan. The health care system in Japan provides services with the patient accepting responsibility for $30 \%$ of these costs while the government pays the remaining 70\%. Japan has a healthcare system that costs half as much and often achieves better medical outcomes than its American counterpart. The healthcare insurance includes publicly financed health insurance, i.e. the PHIS (public health insurance system), and private health insurance, which plays a supplementary role. However, many health economists say Japan's low-cost system is probably not sustainable without significant change. For example, to keep the costs down, most of Japanese doctors make far less than their US counterparts with way more working loads; and also the moral hazard, due to the equal treatment to all patients, hurts the medical system as well. 
Our results also demonstrate the efficiency of insurance mandate healthcare system when we evaluate the total healthcare administration costs. Switzerland, as an example of insurance mandate healthcare system, displays a more efficient way of operation than the US, who has the similar healthcare system. Healthcare in Switzerland is regulated by the Swiss Federal Law on Health Insurance. There are no free state-provided health services, but private health insurance is compulsory for all persons residing in Switzerland. The example of the Swiss system shows a) that the consumer-driven model does not work to control the costs and b) the irrelevancy of the argument over whether individuals are consumers at all [18]. Switzerland also has amongst the highest life expectancy in the world, and positive patient satisfaction reflect the high performance of the healthcare system, with a relative high healthcare expenditure, which is still much lower than how much the US spend on healthcare.

Our goal of this research is actually pointing out a direction for the US healthcare reforms using empirical proof, which has been argued over decades, especially after the Obamacare has been activated in 2010. Our research results, indeed, illustrate that besides single-payer system; all other healthcare system could perform the same level of healthcare outcomes, or even provide better medical results for patients or residents, with same or even lower administration costs. Comparing with single-payer system, two-tier system and insurance mandate system also reveal several advantages. To save on healthcare administration costs without harming the quality of care and health outcomes, the US federal government may look over more examples or experiences from other countries and other healthcare systems.

\section{References}

[1] Steffie, W. (2003) Terry Campbell, and David Himmelstein. Costs of Health Care Administration in the United States and Canada. The New England Journal of Medicine, 3, 768-775.

[2] Yu, J. (2016) Avoidable Mortality and Healthcare Expenditure in OECD Countries: DEA and SFA Methods to Health Expenditure Efficiency. Journal of Advances in Social Science \& Humanities, 2, 25-36.

[3] David, S. and Chloe, A. (2015) U.S. Health Care from a Global Perspective: Spending, Use of Services, Prices and Health in 13 Countries. The Commonwealth Fund, New York.

[4] Alanna, P. (2017) U.S. Health Care Admin Costs Are Double the Average. CNN Money, Atlanta.

[5] Health Canada 2013a (2014) Canada Health Act Annual Report 2012-2013. Ottawa: Minister of Health of Canada, Ottawa.

[6] Canadian Institute for health Information 2015a (2015) National Health Expenditure Trends 1975-2015. Canadian Institute for Health Information, Ottawa.

[7] AIHW (2014) Australia’s Health 2014. Australian Government, Canberra.

[8] National Institute of Population and Social Security Research (2014) Social Security in Japan. National Institute of Population and Social Security Research, Tokyo.

[9] Ellis, R.P., Chen, T.X. and Calvin, E.L. (2014) Compatisons of Health Insurance 
Systems in Developed Countries. In Culyer, A., Ed., Encyclopedia of Health Economics, Elsevier, Amsterdam. https://doi.org/10.1016/B978-0-12-375678-7.00905-6

[10] Joao, M. and Schwierz, C. (2015) Efficiency Estimates of Health Care Systems. European Commission, Brussels.

[11] Elias, M., Wenzl, M., Osborn, R. and Sarnak, D. (2016) 2015 International Profiles of Health Care Systems. The Commonwealth Fund, New York.

[12] Goran, R., Gleason, S. and Ridic, O. (2012) Comparisons of Health Care Systems in the United States, Germany and Canada. Material Socio Medica, 24, 112-120. https://doi.org/10.5455/msm.2012.24.112-120

[13] Alexis, P. and David, M.C. (2010) Medical Spending Differences in the United States and Canada: The Rold of Prices, Procedures, and Administrative Expenses. Inquiry, 47, 124-134. https://doi.org/10.5034/inquiryirnl 47.02.124

[14] Charnes, A., Cooper, W.W. and Rhodes, E. (1978) Measuring the Efficiency of Decision Making Units. European Journal of Operational Research, 2, 429-444. https://doi.org/10.1016/0377-2217(78)90138-8

[15] Ageliki, F., Kontodimopoulos, N. and Niakas, D. (2011) Employing Post_DEA Cross-Evaluation and Cluster Analysis in a Sample of Greek NHS Hospitals. Journal of Medical Systems, 35, 1001-1014. https://doi.org/10.1007/s10916-010-9533-9

[16] Banker, R.D., Charnes, A. and Cooper, W.W. (1984) Some Models for Estimating Techinical and Scale Inefficiencies in Data Envelopment Analaysis. Management Science, 30, 1078-1092. https://doi.org/10.1287/mnsc.30.9.1078

[17] Jonathan, G. (2009) The Case for a Two-Tier Health System. Pathways, Los Angeles.

[18] Avik, R. (2011) Why Switzerland Has the World's Best Health Care System. Forbes, Jersey City.

\section{Submit or recommend next manuscript to SCIRP and we will provide best service for you:}

Accepting pre-submission inquiries through Email, Facebook, LinkedIn, Twitter, etc. A wide selection of journals (inclusive of 9 subjects, more than 200 journals) Providing 24-hour high-quality service User-friendly online submission system Fair and swift peer-review system Efficient typesetting and proofreading procedure Display of the result of downloads and visits, as well as the number of cited articles Maximum dissemination of your research work

Submit your manuscript at: http://papersubmission.scirp.org/

Or contact me@scirp.org 